\title{
How much difference does DSM-5 make? A longitudinal evaluation of DSM-IV and DSM-5 eating disorders in a population-based cohort of adolescents
}

\author{
Karina Allen ${ }^{1,2^{*}}$, Susan Byrne ${ }^{2}$, Wendy Oddy ${ }^{1}$, Ross Crosby ${ }^{3,4}$ \\ From 2013 ANZAED Conference: Inspiring Change: Person and Context \\ Melbourne, Australia. 23-24 August 2013
}

\section{Aims}

This study aimed to provide data on the relative prevalence of DSM-IV and DSM-5 eating disorders at three time points in adolescence, for males and females. It also aimed to examine associations between DSM-IV and DSM-5 eating disorders and depressive symptoms and quality of life.

\section{Methods}

Participants (N=1,383; 49\% male) were drawn from the Western Australian Pregnancy Cohort (Raine) Study, a prospective, population-based cohort study that has followed participants from pre-birth to young adulthood. Changes in eating disorder prevalence over time were considered using generalised estimating equations.

\section{Results}

Eating disorder prevalence rates increased significantly from age 14 to age 20, irrespective of the diagnostic system used. The prevalence of DSM-5 eating disorders was significantly higher than the prevalence of DSM-IV eating disorders for females, but not for males. 'Unspecified' eating disorders were significantly less common when applying DSM-5 than DSM-IV criteria, for males and females, but still accounted for $15 \%$ to $40 \%$ of the DSM-5 cases. All eating disorder diagnoses were associated with depressive symptoms and poor mental health quality of life.

\section{Conclusions}

Results provide further support for the clinical utility of DSM-5 eating disorder criteria, and for the significance of binge eating disorder and 'not elsewhere classified' disorders.

This abstract was presented in the Understanding and Treating Eating Pathology stream of the 2013 ANZAED Conference.

\section{Authors' details}

${ }^{1}$ Centre for Child Health Research, Telethon Institute for Child Health Research, Australia. ${ }^{2}$ School of Psychology, The University of Western Australia, Australia. ${ }^{3}$ Department of Clinical Neuroscience, University of North Dakota School of Medicine and Health Sciences, USA. ${ }^{4}$ Department of Biostatistics, Neuropsychiatric Research Institute, USA.

Published: 14 November 2013

doi:10.1186/2050-2974-1-S1-064

Cite this article as: Allen et al.: How much difference does DSM-5 make? A longitudinal evaluation of DSM-IV and DSM-5 eating disorders in a population-based cohort of adolescents. Journal of Eating Disorders 2013 1(Suppl 1):O64.

\footnotetext{
* Correspondence: karina.allen@uwa.edu.au

${ }^{1}$ Centre for Child Health Research, Telethon Institute for Child Health Research, Australia

Full list of author information is available at the end of the article
} 